\title{
ЭФФЕКТИВНОСТЬ ПРИМЕНЕНИЯ ГЕРБИЦИДОВ И СТИМУЛЯТОРОВ РОСТА ПРИ ВОЗДЕЛЫВАНИИ ОЗИМОЙ ТРИТИКАЛЕ
}

\author{
P. N. Kuznetsov, A. S. Vasilyev, \\ L. M. Solovyova
}

\section{THE EFFICIENCY OF USING HERBICIDES AND GROWTH FACTORS IN WINTER TRITICALE CULTIVATION}

Кузнецов Павел Николаевич - д-р с.-х. наук, проф. каф. ботаники и луговых экосистем Тверской государственной сельскохозяйственной академии, г. Тверь. E-mail: pkuznecov@tvgsha.ru

Васильев Александр Сергеевич - канд. с.-х. наук, доц., зав. каф. технологии переработки и хранения сельскохозяйственной продукции Тверской государственной сельскохозяйственной академии, г. Тверь. E-mail: vasilevtgsha@mail.ru

Соловьева Любовь Михайловна - асп. каф. технологии переработки и хранения сельскохозяйственной продукции Тверской государственной сельскохозяйственной академии, г. Тверь. E-mail: solovyovapost@mail.ru

Цель исследований - изучение особенностей формирования засоренности и продуктивности посевов озимой тритикале под влиянием различных гербицидов и стимуляторов роста при использовании разных приемов основной обработки почвы. Задачи исследований: 1) дать оценку формирования засоренности посевов озимой тритикале под влиянием изучаемых приемов; 2) выявить особенности фоорирования продуктивности озимой тритикале при применении различных приемов основной обработки почвы, гербицидов и стимуляторов роста. Исследования проводились на опытном поле Тверской ГСХА в 2016-2018 г2. на дерновоподзолистой супесчаной почве. Схема опыта включала фракторы: A - прием обработки почвы (1 - вспашка отвальным плугом, 2 - дискование в два следа); В - обработка стимулятором роста (1 - без обработки, 2 - «Биоплант Флора», 3 - "Сила Жизни»); С - гербицид (1 - без обработки, 2 - «Эллай Лайт», 3 - «Дианат»). Полученные в результате эксперимента данные выявили положительное действие на-
Kuznetsov Pavel Nikolaevich - Dr. Agr. Sci., Prof., Chair of Botany and Meadow Ecosystems, Tver State Agricultural Academy, Tver.

E-mail: pkuznecov@tvgsha.ru

Vasilyev Alexander Sergeevich - Cand. Agr. Sci., Assoc. Prof., Head, Chair of Technology of Processing and Storage of Agricultural Production, Tver State Agricultural Academy, Tver.

E-mail: vasilevtgsha@mail.ru

Solovyova Lyubov Mikhaylovna - Post-Graduate Student, Chair of Technology of Processing and Storage of Agricultural Production, Tver State Agricultural Academy, Tver.

E-mail: solovyovapost@mail.ru

стоящих препаратов, особенно на фроне отвальной обработки, на основные показатели роста и развития растений, основнье элементы структуры урожая, а также на продуктивность культуры в целом. Максимальная урожайность зерна в опыте была получена при применении в системе ухода за посевами гербицида «Эллай Лайт» в сочетании со стимулятором роста «Биоплант Флора», что обеспечило: по вспашке - 4,72, а по дискованию 4,35 m зерна с 1 га. Прибавка урожая зерна по отношению к контролю соответственно составила 0,60 и 0,47 m/2а.

Ключевые слова: озимая тритикале, гербициды, стимуляторы роста, вспашка, дискование, урожайность.

The purpose of the researches was studying the features of growing contamination and winter triticale crops efficiency under the influence of various herbicides and growth factors when using different methods of the main soil preparation. The research problems were: 1) to give the assessment of the for- 
mation of contamination of winter triticale crops under the influence of studied receptions; 2) to reveal the features of the formation of winter triticale efficiency at application of various methods of the main soil preparation, herbicides and growth factors. The researches were conducted on experimental field of Tver SAA in 2016-2018 on cespitose and podsolic sandy soil. The scheme of the experiment included the factors: $A$ - basic tillage: 1 - Plowing, 2 - Disking; $B$ - Growth stimulator: 1 - Without treatment, 2 - «Bioplant Flora», 3 - «Life Force»; C - Herbicide: 1 - Without treatment, 2 - «Ellay Light», 3 "Dianate». The data obtained as a result of the experiment revealed positive action of real preparations, especially against dump processing, on the main indicators of growth and development of plants, basic elements of crop structure, and also on the efficiency of the culture in general. The maximum grain yield in the experiment was obtained when using the herbicide "Ellay Light» in the system of crop protection in combination with the growth stimulator "Bioplant Flora», which provided: for plowing 4.72, and for disking - 4.35 tons of grain per 1 hectare. The increase in grain yield in relation to the control, was 0.60 and 0.47 thectare, respectively.

Keywords: winter triticale, herbicides, growth stimulants, plowing, disking, crop yield.

Введение. Важной задачей современного аграрного сектора экономики является наращивание производства дешевого и качественного зерна [1-4]. Практическое осуществление указанной задачи невозможно без использования современных агротехнологий, учитывающих почвенноклиматические и ресурсные особенности [5]. Ведущее место при фрормировании эфрфективных технологий выращивания сельскохозяйственных культур уделяется системам защиты посевов от вредных объектов, в частности сорных растений, являющихся главными конкурентами за свет, влагу и питательные вещества [6-9]. Основным методом борьбы с сорной растительностью является применение разнообразных гербицидов, высокая действенность которых в ряде случаев сопряжена с негативным влиянием на культуру различной степени выраженности, что может отрицательно сказаться на ходе продукционного процесса и конечной продуктивности посевов [10, 11]. Снижение или даже полное устранение отмеченных эфффектов может быть достигнуто при применении ростстимулирующих веществ различного, преимущественно органического, происхождения, которые обладают стресспротекторными и иммуномодулирующими свойствами $[11,12]$. Всем перечисленным критериям в наиболее полной мере отвечают препараты на основе гуминовых веществ, способные при попадании в клетки растений связывать ксенобиотики и обладающие экономическими преимуществами, сформировавшимися за счет получения гуматов из местных источников сырья (торф, уголь, сапропель) [11-14]. Особую ценность они имеют для озимых культур, прошедших перезимовку и затрачивающих в весенний период ресурсы на восстановление [12]. Экспериментальные работы в области комплексного применения гербицидов и стимуляторов роста на основе гуминовых веществ при выращивании зерновых культур носят ограниченный характер, что требует проведения дополнительных исследований.

Цель исследований: изучение особенностей формирования засоренности и продуктивности посевов озимой тритикале под влиянием различных гербицидов и стимуляторов роста при использовании разных приемов основной обработки почвы.

\section{Задачи исследований:}

1. Дать оценку формирования засоренности посевов озимой тритикале под влиянием изучаемых приемов.

2. Выявить особенности формирования продуктивности озимой тритикале при применении различных приемов основной обработки почвы, гербицидов и стимуляторов роста.

Материалы и методы исследований. Исследования проводились в 2017-2018 гг. на опытном поле ФГБОУ ВО Тверской ГСХА, г. Тверь. Посев озимой тритикале в рамках закладки полевого опыта был осуществлен в 2016 г. Почва под опытами - дерново-подзолистая супесчаная, характеризовалась содержанием в пахотном слое: гуму$\mathrm{ca}-2 \%, \mathrm{P}_{2} \mathrm{O}_{5}-270-290$ и К $2 \mathrm{O}-90-100$ мг/кг почвы, $\mathrm{pH}_{\text {сол }}-6,8$ ед.

Схема опыта включала: фактор A - прием обработки почвы (1 - вспашка отвальным плугом (на глубину 20-22 см), 2 - дискование в два следа (на глубину 10-12 см)); фрактор В - защитно-стимулирующая обработка посевов (1 без обработки (контроль), 2 - «Биоплант Флора» $(1,0$ л/га), 3 - «Биоплант Флора» $(1,0$ л/га) + 
«Эллай Лайт» (6 г/га), 4 - «Биоплант Флора» $(1,0$ л/га) + «Дианат» $(0,3$ л/га), 5 - «Сила жизни» (1,0 л/га), 6 - «Сила жизни» $(1,0$ л/га) + «Эллай Лайт» (6 г/га), 7 - «Сила жизни» $(1,0$ л/га) + «Дианат» (0,3 л/га)).

Объекты исследований: озимая тритикале сорта Немчиновская 56; удобрение на основе гуминовых кислот с микроэлементами «Биоплант Флора» (ООО «Плант»); комплексное органоминеральное удобрение на основе гуминовых кислот «Сила жизни» (НПО «Сила жизни»); гербицид «Эллай Лайт», ВДГ, д.В. метсульфруронметил (391 г/кг) + трибенурон-метил (261 г/кг) (ООО «Дюпон Наука и Технологии»); гербицид «Дианат», ВР, д.В. дикамба (диметиламинная соль) (480 г/л) (БАСФ).

Повторность в опыте 4-кратная, размер делянки 40 м², при длине 10 м и ширине 4 м. Учетная площадь $-20 \mathrm{~m}^{2}$.

Агротехника озимой тритикале была общепринятой для региона с трансформацией отдельных приемов согласно принятой схеме опыта. Норма расхода рабочей жидкости при обработках стимуляторами роста и гербицидами, осуществляемых в период устойчивого весеннего кущения озимых и массовом появлении всходов сорных растений, составляла 300 л/га.

Гидротермические условия вегетационного периода в годы исследований были различными по основным показателями, обеспечивая полноту выявления закономерностей воздействия на посевы озимой тритикале изучаемых факторов: 2017 г. - ¿t (сумма активных температур) $>10{ }^{\circ} \mathrm{C}$ $=1869(97,1 \%$ от нормы), $\Sigma \mathrm{W}$ (сумма осадков) $=$ 272 мм (92,5\%), ГТК по Селянинову = 1,46 (104,8 $\%$ ), ФАР (приход фотосинтетически активной радиации) $=104,2$ кДж/см² (100,6 \%), R (радиационный баланс) $=126,1$ кДж/см² (97,7 \%); 2018 г. $\Sigma t>10{ }^{\circ} \mathrm{C}=2239(116,3 \%), \quad \Sigma W=222 \mathrm{~mm}$ $(75,5 \%)$, ГТК по Селянинову $=0,99(64,7 \%)$,

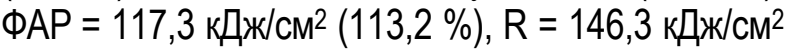
$(113,3 \%)$.

Запланированные в опыте исследования и наблюдения проводились по хорошо апробированным методикам: засоренность (в сроки: в фазе весеннего кущения, через 21 день после защитно-стимулирующей обработки, перед уборкой урожая) - по И. П. Васильеву (2004) [15], густота продуктивного стеблестоя и высота растений по 3. И. Усановой (2015) [16], учет урожая - ме- тодом сплошной поделяночной уборки комбайном Sampo-Terrion 2010, математическая обработка - по Б. А. Доспехову (1985) [17].

Результаты исследований и их обсуждение. Исследованиями выявлено, что при выращивании озимой тритикале в посевах были обнаружены в основном малолетние двудольные виды, представленные биогруппами: эфремеры звездчатка средняя (Stellaria media (L.) Vill.), яровые ранние - лебеда раскидистая (Atriplex patula L.), мать-и-мачеха (Tussilágo farfarae L.), марь белая (Chenopodium album L.) и яровые поздние - щирица запрокинутая (Amaranthus retroflextis L.). Кроме этого, были выявлены многолетние корнеотпрысковые сорняки осот полевой (Sonchus arvensis L.) и бодяк полевой (Cursium arvense (L.) Scop.). Представители класса однодольных во время учетов выявлены не были, что объясняется широким применением в севообороте при выращивании двудольных культур (картофель, лен-долгунец) противозлаковых гербицидов. Следует отметить, что исходные численность и масса сорных растений

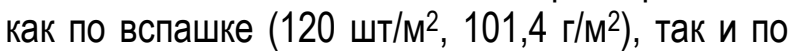

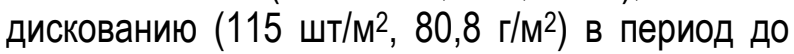
обработки посевов соответствовали высокой степени засорения (табл. 1).

Наибольшим влиянием на засоренность посевов характеризовалась обработка растений гербицидами в комплексе со стимуляторами роста. Так, биологическая эфффективность гербицидов составила - «Эллай Лайт» по вспашке 84$87 \%$, по дискованию $79 \%$, «Дианат» соответственно 64-68 и 59-63 \%. Применение для основной обработки почвы агрегата с активными рабочими органами - дисковой бороны относительно отвальной вспашки способствовало повышению интенсивности воздействия на верхнюю часть пахотного слоя, обеспечивая снижение засоренности посевов в начале и середине вегетации. Однако существенное засорение пахотного слоя почвы семенами сегеталов, а также улучшение их размещения по профилю практически полностью нивелировало данный эфффект к периоду уборки тритикале. В целом минимализация обработки почвы изменяла агроэкологические условия функционирования агрофитоценоза и увеличивала количество злостных многолетних сорняков - осота полевого и бодяка полевого, а также высококонкурентного малолетнего сорняка - 
мари белой. Указанные сорные виды отличались ранним прорастанием, интенсивным развитием, значительной агрессивностью. Все вышеперечисленное способствовало снижению действенности гербицидов на фоне дискования относительно отвальной вспашки на 16-20\%. Следует отметить, что более высокой биологической эффективностью по доминирующим видам сегетальной растительности в посевах озимой тритикале отличался гербицид «Эллай Лайт», обеспечивший уничтожение их значительной части (82-86 \%).

Таблица 1

Засоренность посевов озимой тритикале (в среднем за 2017-2018 гг.)

\begin{tabular}{|c|c|c|c|c|c|c|c|c|}
\hline \multirow{3}{*}{$\begin{array}{l}\text { Обработка } \\
\text { почвы (А) }\end{array}$} & \multirow{2}{*}{\multicolumn{2}{|c|}{$\begin{array}{c}\text { Защитно-стимулирующая } \\
\text { обработка посевов (В) }\end{array}$}} & \multicolumn{6}{|c|}{ Срок проведения учетов } \\
\hline & & & \multicolumn{2}{|c|}{ До обработки } & \multicolumn{2}{|c|}{ После обработки } & \multicolumn{2}{|c|}{ Перед уборкой } \\
\hline & $\begin{array}{c}\text { Стимулятор } \\
\text { роста }\end{array}$ & Гербицид & $\begin{array}{l}\text { Число, } \\
\text { шт/M² }\end{array}$ & $\begin{array}{c}\text { Сырая } \\
\text { мacca, } \\
\text { г/M² }\end{array}$ & $\begin{array}{l}\text { Число, } \\
\text { шт/м² }\end{array}$ & $\begin{array}{l}\text { Сырая } \\
\text { масcа, } \\
\text { г/M² }\end{array}$ & $\begin{array}{l}\text { Число, } \\
\text { шт/м² }\end{array}$ & $\begin{array}{c}\text { Сырая } \\
\text { мacca, } \\
\Gamma / \mathrm{M}^{2}\end{array}$ \\
\hline \multirow{7}{*}{$\begin{array}{c}\text { Вспашка } \\
\text { (на глубину } \\
20-22 \text { см) }\end{array}$} & - & - & 120 & 101,4 & 129 & 143,8 & 113 & 89,6 \\
\hline & \multirow{3}{*}{$\begin{array}{c}\text { Биоплант } \\
\text { Флора }\end{array}$} & - & - & - & - & - & - & - \\
\hline & & Эллай Лайт & 119 & 110,7 & 15 & 18,9 & 53 & 50,1 \\
\hline & & Дианат & 123 & 146,2 & 39 & 50,1 & 74 & 66,3 \\
\hline & \multirow{3}{*}{ Сила жизни } & - & - & - & - & - & - & - \\
\hline & & Эллай Лайт & 125 & 150,0 & 20 & 23,8 & 58 & 60,2 \\
\hline & & Дианат & 123 & 121,4 & 44 & 60,0 & 67 & 63,4 \\
\hline \multirow{7}{*}{$\begin{array}{c}\text { Дискование } \\
\text { (на глубину } \\
10-12 \text { см) }\end{array}$} & - & - & 115 & 80,8 & 121 & 126,1 & 117 & 74,8 \\
\hline & \multirow{3}{*}{$\begin{array}{l}\text { Биоплант } \\
\text { Флора }\end{array}$} & - & - & - & - & - & - & - \\
\hline & & Эллай Лайт & 105 & 80,1 & 22 & 30,4 & 61 & 63,5 \\
\hline & & Дианат & 127 & 140,6 & 52 & 60,9 & 95 & 90,8 \\
\hline & \multirow{3}{*}{ Сила жизни } & - & - & - & - & - & - & - \\
\hline & & Эллай Лайт & 118 & 100,2 & 25 & 33,5 & 68 & 69,0 \\
\hline & & Дианат & 110 & 95,8 & 41 & 48,0 & 72 & 76,3 \\
\hline
\end{tabular}

Роль применения стимуляторов роста «Биоплант Флора» и «Сила жизни» в опыте состояла не только в усилении жизненности растений, но и, главным образом, в сглаживании ксенобиотического воздействия на озимую тритикале химических средств защиты, что подтверждается результатами и других авторов $[11,12]$.

Наименьшая в опыте засоренность посевов

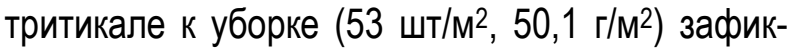
сирована при отвальной обработке почвы и применении защитно-стимулирующей обработки почвы гербицидом «Эллай Лайт» и препаратом «Биоплант Флора».

Процесс создания высокопродуктивных посевов зерновых культур непосредственно связан с габитусом растений и количеством продуктивных соцветий у одного злака. Учет числа продуктивных побегов озимой тритикале перед уборкой показал, что их значения в опыте были ниже оптимальных показателей, равных 450-500 шт/м² [16] (табл. 2). Данное явление объяснялось плохими условиями перезимовки растений и вследствие этого значительным изреживанием посевов, которое не смогло быть компенсировано в ходе весеннего кущения.

Наибольшее количество продуктивных побегов, а также максимальная высота растений в опыте были сформированы как при отвальной вспашке, так и при дисковании в условиях опрыскивания посевов гербицидом «Эллай Лайт» и стимулятором роста «Биоплант Флора», соответственно 283 шт/м²; 126,3 см и 267 шт/M²; 122,6 см. При этом более высокие значения численности продуктивных побегов и высоты растений отмечались по вспашке. В этой связи определенный интерес представляет многолетний эксперимен- 
тальный материал, полученный в аналогичных условиях на озимой пшенице, где вспашка на различных фонах минерального питания также способствовала более высокому количеству продуктивных стеблей - 422-434 шт/м², тогда как при обработке в два следа количество продуктивных стеблей не превышало 398-412 шт/M² [1]. Данная закономерность объясняется степенью воздействия рабочих органов сельскохозяйственных ма- шин на почву, в частности на дерново-подзолистых почвах проведение отвальной вспашки сопровождается расширением эффрективного плодородия почвы за счет уменьшения дифференциации пахотного слоя почвы, увеличения в почве подвижных форм Р и К, снижения иммобилизации азота в процессе минерализации растительных остатков [18].

\section{Густота продуктивного стеблестоя и высота озимой тритикале}

Таблица 2

\begin{tabular}{|c|c|c|c|c|c|c|c|c|}
\hline \multirow{2}{*}{$\begin{array}{l}\text { Обработка } \\
\text { почвы (A) }\end{array}$} & \multicolumn{2}{|c|}{$\begin{array}{c}\text { Защитно-стимулирующая } \\
\text { обработка посевов (B) }\end{array}$} & \multicolumn{3}{|c|}{$\begin{array}{c}\text { Число продуктивных } \\
\text { побегов, шт/м² }\end{array}$} & \multicolumn{3}{|c|}{$\begin{array}{c}\text { Высота растений } \\
\text { к уборке, см }\end{array}$} \\
\hline & $\begin{array}{c}\text { Стимулятор } \\
\text { роста }\end{array}$ & Гербицид & 2017 г. & 2018 г. & Среднее & 2017 г. & 2018 г. & $\begin{array}{l}\text { Сред- } \\
\text { нее }\end{array}$ \\
\hline \multirow{7}{*}{$\begin{array}{c}\text { Вспашка } \\
\text { (на глубину } \\
20-22 \text { см) }\end{array}$} & - & - & 191 & 196 & 194 & 117,3 & 116,0 & 116,6 \\
\hline & \multirow{3}{*}{$\begin{array}{l}\text { Биоплант } \\
\text { Флора }\end{array}$} & - & 240 & 206 & 223 & 119,7 & 120,5 & 120,1 \\
\hline & & Эллай Лайт & 349 & 217 & 283 & 124,4 & 128,1 & 126,3 \\
\hline & & Дианат & 281 & 209 & 245 & 116,2 & 122,7 & 119,5 \\
\hline & \multirow{3}{*}{ Сила жизни } & - & 227 & 196 & 212 & 118,2 & 117,9 & 118,1 \\
\hline & & Эллай Лайт & 331 & 206 & 269 & 121,3 & 119,1 & 120,2 \\
\hline & & Дианат & 274 & 204 & 239 & 116,4 & 118,5 & 117,5 \\
\hline \multirow{7}{*}{$\begin{array}{c}\text { Дискование } \\
\text { (на глубину } \\
10-12 \text { см) }\end{array}$} & - & - & 184 & 186 & 185 & 116,4 & 113,2 & 114,8 \\
\hline & \multirow{3}{*}{$\begin{array}{l}\text { Биоплант } \\
\text { Флора }\end{array}$} & - & 227 & 196 & 212 & 119,1 & 117,6 & 118,3 \\
\hline & & Эллай Лайт & 331 & 203 & 267 & 120,7 & 124,6 & 122,6 \\
\hline & & Дианат & 265 & 196 & 231 & 116,0 & 118,4 & 117,2 \\
\hline & \multirow{3}{*}{ Сила жизни } & - & 251 & 187 & 219 & 118,3 & 114,6 & 116,5 \\
\hline & & Эллай Лайт & 306 & 195 & 251 & 119,9 & 115,9 & 117,9 \\
\hline & & Дианат & 258 & 190 & 224 & 115,0 & 115,5 & 115,3 \\
\hline
\end{tabular}

Отмеченные закономерности в формировании свойств почвы и посевов при разных почвообработках оказали влияние и на образование урожая (табл. 3). Так, применение в системе основной обработки почвы отвальной вспашки повышало урожайность зерна на 0,24 т/га (6,2 \%).

Максимальный сбор зерна был получен при применении гербицида «Эллай Лайт» в сочетании со стимулятором роста «Биоплант Флора», обеспечивших: по вспашке - 4,72, а по дискова- нию - 4,35 т/га. Прибавка урожая зерна по отношению к варианту без защитно-стимулирующей обработки составила соответственно 0,60 и 0,47 т/га, или 14,6 и 11,3 \%. Заметим, что обработка посевов тритикале гербицидом «Дианат» в комплексе с вышеуказанным биостимулятором способствовала прибавке урожая 0,37 т/га (9,0 \%) по вспашке и 0,32 т/га $(7,4$ \%) при дисковании. 
Урожайность озимой тритикале, т/га

\begin{tabular}{|c|c|c|c|c|c|c|c|}
\hline \multirow{2}{*}{$\begin{array}{c}\text { Обработка } \\
\text { почвы (A) }\end{array}$} & \multicolumn{2}{|c|}{$\begin{array}{c}\text { Защитно-стимулирующая } \\
\text { обработка посевов (В) }\end{array}$} & \multirow{2}{*}{2017 г. } & \multirow{2}{*}{2018 г. } & \multirow{2}{*}{ Среднее } & \multicolumn{2}{|c|}{$\begin{array}{c}\text { Прибавка } \\
\text { урожайности }\end{array}$} \\
\hline & $\begin{array}{c}\text { Стимулятор } \\
\text { роста }\end{array}$ & Гербицид & & & & т/га & $\%$ \\
\hline \multirow{7}{*}{$\begin{array}{c}\text { Вспашка } \\
\text { (на глубину } \\
20-22 \text { см) }\end{array}$} & - & - & 4,38 & 3,86 & 4,12 & 0,0 & 0,0 \\
\hline & \multirow{3}{*}{$\begin{array}{c}\text { Биоплант } \\
\text { Флора }\end{array}$} & - & 4,57 & 4,24 & 4,41 & 0,29 & 7,0 \\
\hline & & Эллай Лайт & 4,89 & 4,55 & 4,72 & 0,60 & 14,6 \\
\hline & & Дианат & 4,64 & 4,34 & 4,49 & 0,37 & 9,0 \\
\hline & \multirow{3}{*}{ Сила жизни } & - & 4,49 & 3,98 & 4,24 & 0,12 & 2,9 \\
\hline & & Эллай Лайт & 4,68 & 4,22 & 4,45 & 0,33 & 8,0 \\
\hline & & Дианат & 4,50 & 4,14 & 4,32 & 0,20 & 4,9 \\
\hline \multirow{7}{*}{$\begin{array}{c}\text { Дискование } \\
\text { (на глубину } \\
10-12 \text { см) }\end{array}$} & - & - & 4,21 & 3,55 & 3,88 & 0,0 & 0,0 \\
\hline & \multirow{3}{*}{$\begin{array}{l}\text { Биоплант } \\
\text { Флора }\end{array}$} & - & 4,44 & 3,88 & 4,16 & 0,28 & 7,2 \\
\hline & & Эллай Лайт & 4,60 & 4,10 & 4,35 & 0,47 & 11,3 \\
\hline & & Дианат & 4,43 & 3,96 & 4,20 & 0,32 & 7,4 \\
\hline & \multirow{3}{*}{ Сила жизни } & - & 4,39 & 3,63 & 4,01 & 0,13 & 3,1 \\
\hline & & Эллай Лайт & 4,46 & 3,86 & 4,16 & 0,28 & 7,0 \\
\hline & & Дианат & 4,40 & 3,72 & 4,06 & 0,18 & 4,3 \\
\hline \multicolumn{3}{|c|}{$\mathrm{HCP}_{05}$ для фактора A } & 0,05 & 0,10 & 0,12 & - & - \\
\hline \multicolumn{3}{|c|}{ НСР 05 для фрактора В } & 0,06 & 0,12 & 0,13 & - & - \\
\hline \multicolumn{3}{|c|}{ НСР05 для взаимодействия АВ } & 0,08 & 0,13 & 0,16 & - & - \\
\hline
\end{tabular}

Выводы. В ходе комплексных исследований выявлено, что доминирующими видами сорных растений в посевах озимой тритикале были малолетние двудольные виды, представленные биогруппами: эфемеры - звездчатка средняя (Stellaria media (L.) Vill.), яровые ранние - лебеда раскидистая (Atriplex patula L.), мать-имачеха (Tussilágo farfarae L.), марь белая (Chenopodium album L.), яровые поздние - щирица запрокинутая (Amaranthus retroflextis L.), a также многолетние корнеотпрысковые сорняки осот полевой (Sonchus arvensis L.) и бодяк полевой (Cursium arvense (L.) Scop.). Исходная численность и масса сорных растений как по вспашке $\left(120\right.$ шт/ $\left./ \mathrm{M}^{2}, 101,4 \mathrm{r} / \mathrm{M}^{2}\right)$, так и по дискованию $(115$ шт/M², 80,8 r/M²) в период до обработки посевов соответствовала высокой степени засорения. Биологическая эфффективность гербицидов составила: «Эллай Лайт» по вспашке 84-87, по дискованию 79 \%; «Дианат» соответственно 64-68 и 59-63 \%. Максимальный сбор зерна был получен при применении гербицида «Эллай Лайт» в сочетании со стимулятором роста «Биоплант Флора», обеспечивших: по вспашке - 4,72, а по дискованию - 4,35 т/га с прибавками, по отношению к варианту без за- щитно-стимулирующей обработки соответственно 0,60 и 0,47 т/га, или 14,6 и 11,3\%.

В качестве перспективы развития данных исследований следует рассматривать изучение возможности использования гербицида «Эллай Лайт» и стимулятора роста «Биоплант Флора» в составе баковых смесей гербицидов, что позволило бы дополнительно усилить биологическую эфффективность химпрополки посевов озимой тритикале.

\section{Литература}

1. Васильев А.С. Особенности продукционного процесса озимых зерновых культур в зависимости от условий основной обработки почвы и минерального питания // Молочнохозяйственный вестник. 2017. № 3. С. 26-39.

2. Кураченко Н.Л., Шаропатова А.В. Эффрективность применения биологического стимулятора «Гипергрин» при возделывании яровой пшеницы в условиях Красноярской лесостепи // Вестник КрасГАУ. 2019. № 12. C. 49-56. DOI: 10.36718/1819-4036-2019-1249-56. 
3. Митрофранов Ю.И. и др. Озимая тритикале на осушаемых землях // Вестник российской сельскохозяйственной науки. 2020. № 1. C. 42-46. DOI: $10.30850 / \mathrm{vrsn} / 2020 / 1 / 42-46$.

4. Турбаев А.Ж., Мергалиев Н.Х., Соловьев А.А. Сравнительное изучение сортообразцов яровой тритикале по показателям качества зерна // Известия ТСХА. 2019. № 1. С. 19-33.

5. Дубовик Д.В., Лазарев В.И., Айдиев А.Я., Ильин Б.С. Эфффективность различных способов основной обработки почвы и прямого посева при возделывании озимой пшеницы на черноземных почвах // Достижения науки и техники АПК. 2019. Т. 33, № 12. С. 26-29. DOI: 10.24411/0235-2451-2019-11205.

6. Зуза В.С. Модель потерь урожая сельскохозяйственных культур в зависимости от засоренности посева // Агрохимия. 2016. № 8. C. 62-67.

7. Gaba S. et al. Response and effect traits of arable weeds in agroecosystems: a review of current knowledge // Weed Research. 2017. Vol. 57. Issue 3. P. 123-147. DOI: 10.1111/wre.12245.

8. Артемьев А.А., Гурьянов А.М. Влияние технологий применения минеральных удобрений на засоренность полевого севооборота // Аграрная наука Евро-СевероВостока. 2018. T. 67, № 6. С. 109-114. DOI: 10.30766/2072-9081.2018.67.6.109-114.

9. Pakeman R.J. et al. Increased crop diversity reduces the functional space available for weeds // Weed Research. 2020. Vol. 60. Issue 2. P. 121-131. DOI: $10.1111 /$ wre.12393.

10. Young S.L. et al. Moving integrated weed management from low level to a truly integrated and highly specific weed management system using advanced technologies // Weed Research. 2017. Vol. 57. Issue 1. P. 1-5. DOI: 10.1111/wre.12234.

11. Федотова О.В., Грехова И.В. Оптимальная доза препарата Росток в баковой смеси с гербицидом на яровой пшенице // Мир инноваций. 2018. № 1-2. С. 90-94.

12. Наими О.И. и др. Эффрективность совместного применения гуминовых препаратов со средствами защиты на зерновых культурах // Известия Оренбургского ГАУ. 2019. № 5. C. 47-51.
13. Корсаков К.В., Стрижков Н.И., Пронько В.В. Совместное применение удобрений, гербицидов и регуляторов роста при возделывании овса и проса в Поволжье // Вестн. Алтайского гос. аграр. ун-та. 2013. № 4 (102). C. 16-19.

14. Грехова И.В., Матвеева Н.В. Применение гуминового препарата в баковой смеси при протравливании семян яровой пшеницы // Проблемы и перспективы биологического земледелия: мат-лы междунар. науч.-практ. конф. Ростов н/Д., 2014. С. 121-127.

15. Васильев И.П. и др. Практикум по земледелию. М.: КолосС, 2004. 424 с.

16. Усанова 3.И. Методика выполнения научных исследований по растениеводству: учеб. пособие. Тверь: Тверская ГСХА, 2015. $143 \mathrm{c}$.

17. Доспехов Б.А. Методика полевого опыта (с основами статистической обработки результатов исследований). М.: Агропромиздат, $1985.351 \mathrm{C}$.

18. Баздырев Г.И., Заверткин И.А. Возможности и проблемы минимализации обработки почвы при длительном ее использовании // Известия ТСХА. 2008. № 4. С. 4-16.

\section{Literatura}

1. Vasil'ev A.S. Osobennosti produkcionnogo processa ozimyh zernovyh kul'tur $v$ zavisimosti ot uslovij osnovnoj obrabotki pochvy i mineral'nogo pitanija // Molochnohozjajstvennyj vestnik. 2017. № 3. S. 26-39.

2. Kurachenko N.L., Sharopatova A.V. Jeffektivnost' primenenija biologicheskogo stimuljatora "Gipergrin» pri vozdelyvanii jarovoj pshenicy v uslovijah Krasnojarskoj lesostepi // Vestnik Kras-GAU. 2019. № 12. S. 49-56. DOI: 10.36718/1819-4036-2019-12-49-56.

3. Mitrofanov Ju.I. i dr. Ozimaja tritikale na osushaemyh zemljah // Vestnik rossijskoj sel'skohozjajstvennoj nauki. 2020. № 1. S. 4246. DOI: $10.30850 / v r s n / 2020 / 1 / 42-46$.

4. Turbaev A.Zh., Mergaliev N.H., Solov'ev A.A. Sravnitel'noe izuchenie sortoobrazcov jaro-voj tritikale po pokazateljam kachestva zerna // Izvestija TSHA. 2019. № 1. S. 19-33.

5. Dubovik D.V., Lazarev V.I., Ajdiev A.Ja., Il'in B.S. Jeffektivnost' razlichnyh sposobov 
osnovnoj obrabotki pochvy i prjamogo poseva pri vozdelyvanii ozimoj pshenicy na chernozemnyh pochvah // Dostizhenija nauki i tehniki APK. 2019. T. 33. № 12. S. 26-29. DOI: 10.24411/0235-2451-2019-11205.

6. Zuza V.S. Model' poter' urozhaja sel'skohozjajstvennyh kul'tur v zavisimosti ot zasoren-nosti poseva // Agrohimija. 2016. № 8. S. 62-67.

7. Gaba $S$. et al. Response and effect traits of arable weeds in agroecosystems: a review of current knowledge // Weed Research. 2017. Vol. 57. Issue 3. P. 123-147. DOI: 10.1111/wre.12245.

8. Artem'ev A.A., Gurjanov A.M. Vlijanie tehnologij primenenija mineral'nyh udobrenij na zasorennost' polevogo sevooborota // Agrarnaja nauka Evro-Severo-Vostoka. 2018. T. 67, № 6. S. 109-114. DOI: 10.30766/20729081.2018.67.6.109-114.

9. Pakeman R.J. et al. Increased crop diversity reduces the functional space available for weeds // Weed Research. 2020. Vol. 60. Issue 2. P. 121-131. DOI: 10.1111/wre.12393.

10. Young S.L. et al. Moving integrated weed management from low level to a truly integrated and highly specific weed management system using advanced technologies // Weed Research. 2017. Vol. 57. Issue 1. P. 1-5. DOI: 10.1111/wre.12234.

11. Fedotova O.V., Grehova I.V. Optimal'naja doza preparata Rostok $\mathrm{v}$ bakovoj smesi $\mathrm{s}$ gerbi-cidom na jarovoj pshenice // Mir innovacij. 2018. № 1-2. S. 90-94.

12. Naimi O.I. i dr. Jeffektivnost' sovmestnogo primenenija guminovyh preparatov so sredstvami zashhity na zernovyh kul'turah // Izvestija Orenburgskogo GAU. 2019. № 5. S. 47-51.

13. Korsakov K.V., Strizhkov N.I., Pron'ko V.V. Sovmestnoe primenenie udobrenij, gerbici-dov i reguljatorov rosta pri vozdelyvanii ovsa i prosa v Povolzh'e // Vestn. Altajskogo gos. agrar. un-ta. 2013. № 4 (102). S. 16-19.

14. Grehova I.V., Matveeva N.V. Primenenie guminovogo preparata $v$ bakovoj smesi pri protravlivanii semjan jarovoj pshenicy // Problemy i perspektivy biologicheskogo zemledelija: mat-ly mezhdunar. nauch.-prakt. konf. Rostov n/D., 2014. S. 121-127.

15. Vasil'ev I.P. i dr. Praktikum po zemledeliju. M.: KolosS, 2004. $424 \mathrm{~s}$.

16. Usanova Z.I. Metodika vypolnenija nauchnyh issledovanij po rastenievodstvu: ucheb. posobie. Tver': Tverskaja GSHA, 2015. 143 s.

17. Dospehov B.A. Metodika polevogo opyta (s osnovami statisticheskoj obrabotki rezul'tatov issledovanij). M.: Agropromizdat, 1985. $351 \mathrm{~s}$.

18. Bazdyrev G.I., Zavertkin I.A. Vozmozhnosti i problemy minimalizacii obrabotki pochvy pri dlitel'nom ee ispol'zovanii // Izvestija TSHA. 2008. № 4. S. 4-16. 